\title{
PENDAURAN LAHAN TEMPAT PEMBUANGAN AKHIR (TPA) DENGAN PERBAIKAN TANAH SECARA MEKANIS
}

\author{
Indra Bhaswara Purnomosidy ${ }^{1}$, dan Aniek Prihatiningsih ${ }^{2}$ \\ ${ }^{1}$ Program Studi Sarjana Teknik Sipil, Universitas Tarumanagara, Jl. Letjen S. Parman No.1 Jakarta \\ Indra.325170040@stu.untar.ac.id \\ ${ }^{2}$ Program Studi Sarjana Teknik Sipil, Universitas Tarumanagara, Jl. Letjen S. Parman No.1 Jakarta \\ aniekp@ft.untar.ac.id
}

Masuk: 18-01-2021, revisi: 17-02-2021, diterima untuk diterbitkan: 11-02-2021

\begin{abstract}
In recent decades Indonesia has experienced a massive population boom, as such adequate facilities are needed. One thing that can be done is the usage of land for landfills to become the providing land for said infrastructure. This study uses the library research method for its processing or it is also called library research for data comparison. The data sources used are primary and secondary data derived from Google Scholar. The data will be analyzed using descriptive analysis method. The theoretical basis used is the theory of soil improvement methods and the handling of leachate as well as methane gas. The final result of the research is a results comparison of settlement and the bearing capacity of the soil that has undergone improvement and the soil that has not undergone improvement. From the research it can be concluded that the suitable method for landfill improvement is Stone Column.
\end{abstract}

Keywords: Mechanical Soil Improvement; landfills; Settlement; Bearing Capacity

\begin{abstract}
ABSTRAK
Pertumbuhan penduduk di Indonesia dalam beberapa dekade terakhir meningkat sehingga dibutuhkan fasilitas yang memadai, salah satunya dengan pemakaian lahan Tempat Pembuangan Akhir (TPA) menjadi sarana infrastruktur. Penelitian ini menggunakan metode library research yang disebut juga penelitian kepustakaan dengan membandingkan data. Adapun sumber data yang digunakan adalah data-data primer dan sekunder dari Google Scholar. Data akan dianalisis dengan metode deskriptif analisis. Landasan teori digunakan adalah teori Metode Perbaikan Tanah dan penanganan Lindi serta Gas Metana. Hasil akhir dari penelitian adalah perbandingan hasil penurunan dan daya dukung tanah sebelum perbaikan dan setelah perbaikan. Hasil penelitian menunjukkan bahwa metode yang cocok untuk perbaikan tanah TPA menggunakan Stone Column.
\end{abstract}

Kata Kunci: Perbaikan Tanah Mekanis; TPA; Penurunan; Daya Dukung

\section{PENDAHULUAN}

Indonesia sebagai Second World Country (Fulmer,2015) sedang mengalami perkembangan dalam skala massif, baik di daerah, pinggiran kota, maupun dalam kota sendiri. Konsep pembangunan adalah adanya lahan sehingga menciptakan sebuah pasar permintaan terhadap lahan itu sendiri. Berbagai upaya telah dilakukan untuk menangani permintaan itu seperti reklamasi lahan oleh pemerintah di pantai indah kapuk. Selain reklamasi satu hal lain yang bisa dilakukan adalah dengan menggunakan lahan tidak dipakai untuk kegunaan lain. Contoh adalah dengan penggunaan TPA untuk bangunan-bangunan seperti perumahan, pabrik, dan fasilitas publik.

Untuk mengatasi masalah permintaan lahan tersebut dapat diterapkan konsep pendauran ulang lahan TPA yang terletak dalam kota maupun pinggiran kota, yang dapat dijadikan lahan siap dipakai sebagai fasilitas publik ataupun taman rekreasi. Hal ini dapat mengatasi permasalahan kekurangan lahan yang diperlukan untuk pembangunan infrastruktur di kota-kota besar dan disaat bersamaan mengurangi serta mengatasi efek-efek buruk dari TPA terhadap lingkungan disekitar. 


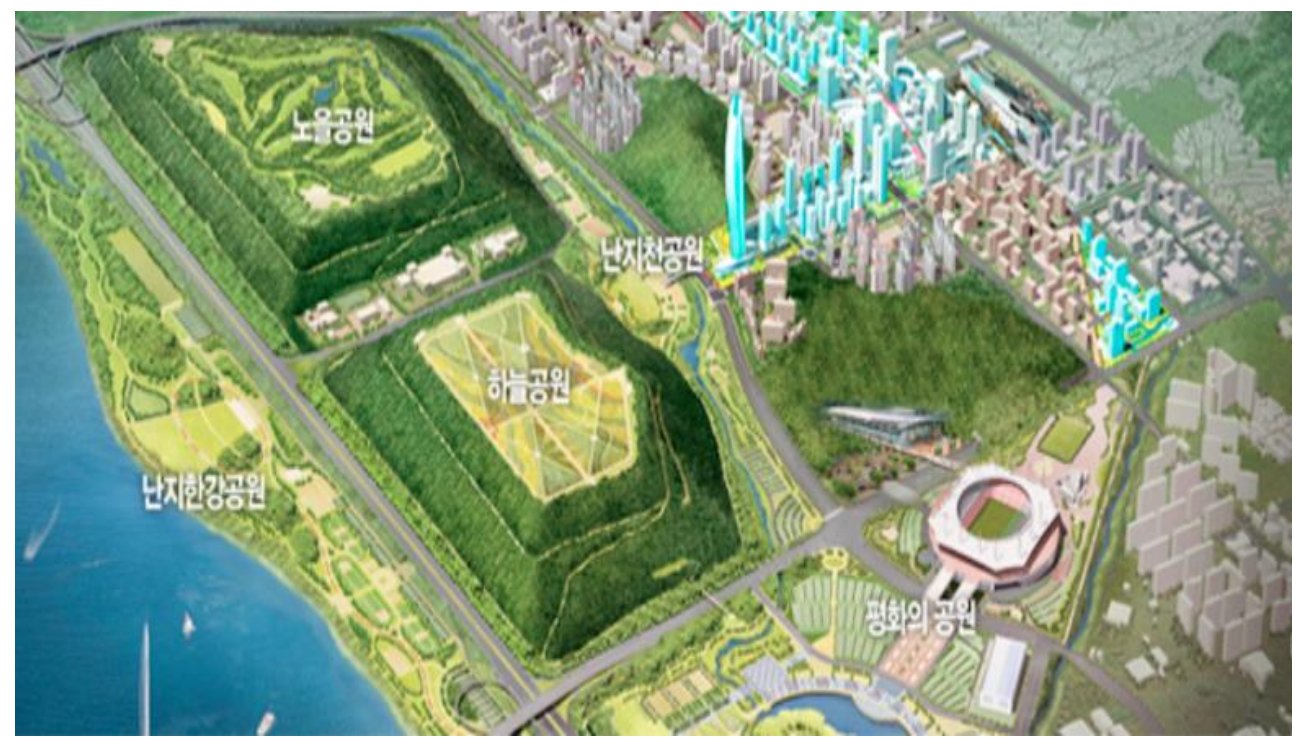

Gambar 1 Stadion Nanjdo beserta Tamannya (Seoul Metropolitan Government, 2015)

Pendauran ulang lahan TPA sudah sering diterapkan di luar negeri, karena dianggap sebagai salah satu solusi terbaik secara ekonomis (Gerth, 2016). Contoh paling terkenal adalah Stadion Nanjido dan taman ekologi Nanjido di Korea yang dibuat untuk mengadakan World Cup 2002, skema stadion bisa dilihat di Gambar 1. Stadion Nanjido dibuat di atas tanah TPA dimana tidak memiliki standar yang memadai untuk dijadikan sebuah Dumping Site seperti pipa penyalur memproses lindi dan gas metana hasil TPA itu sendiri. Tidak hanya di korea, negaranegara barat juga telah mengimplementasikan hal sama, seperti di Amerika dimana sebuah landfill (TPA) diubah menjadi sebuah kompleks perumahan.

Dalam pendauran ulang tanah TPA pembangunan tidak bisa langsung di lakukan karena adanya sampah di lapangan, hal ini tidak saja membuat lingkungan kerja menjadi berbahaya tapi juga dapat menciptakan bencana di proyek. Jika timbunan sampah tersebut mengalami dekomposisi dan terjadi penurunan serta menghasilkan gas metana yang mudah terbakar dapat menyebabkan ledakan yang membahayakan nyawa para pekerja (Yoo, Kim and Kang,2014).

Oleh karena itu sebelum pendauran ulang tanah TPA menjadi lahan yang berguna, diperlukan sebuah memproses penanganan sampah tersebut. Agar sampah yang ada di lapangan tidak mengganggu proses pembangunan maupun integritas struktur tanah itu sendiri. Penanganan tersebut dapat dilakukan dengan berbagai cara diantaranya yakni secara kimia dan mekanis (Darwis,2017). Dalam penulisan ini akan dibahas mengenai perbaikan tanah mekanis pada lahan TPA dan pemanfaatannya.

\section{METODE PENELITIAN}

\section{Studi Literatur}

Metode penelitian yang digunakan dalam penelitian ini adalah metode studi literatur yaitu dengan cara mencari informasi tentang gejala existing, men definisikan dengan jelas tujuan yang akan dicapai, merencanakan cara pendekatannya, mengumpulkan data sebagai bahan untuk membuat laporan dan pengolahannya. Dalam penelitian ini penulis ingin mengetahui atau mengukur keterkaitan antara perbaikan tanah mekanis dan penurunan pada tanah Tempat Pembuangan Akhir (TPA).

\section{Pengelolaan Data}

Pada penelitian ini, data tanah yang akan dianalisis berlokasi di TPA di Amerika (Jedele and Buschmeier,2013). Data tanah berupa grafis nilai NSPT dan hasil tes laboratorium.

\section{Perhitungan Data}

Sebelum dilakukan pengolahan data terlebih dahulu dilakukan studi literatur untuk memahami dasar-dasar teori dan rumus-rumus untuk perhitungan. Data-data dari berbagai sumber tersebut dianalisis secara manual. Dilakukan perhitungan daya dukung ujung dan daya dukung selimut. 
Perhitungan daya dukung ujung berdasarkan teori (Reese \& Wright, 1977). Untuk tanah non-kohesif perhitungan Qp menggunakan grafis sebagai berikut:

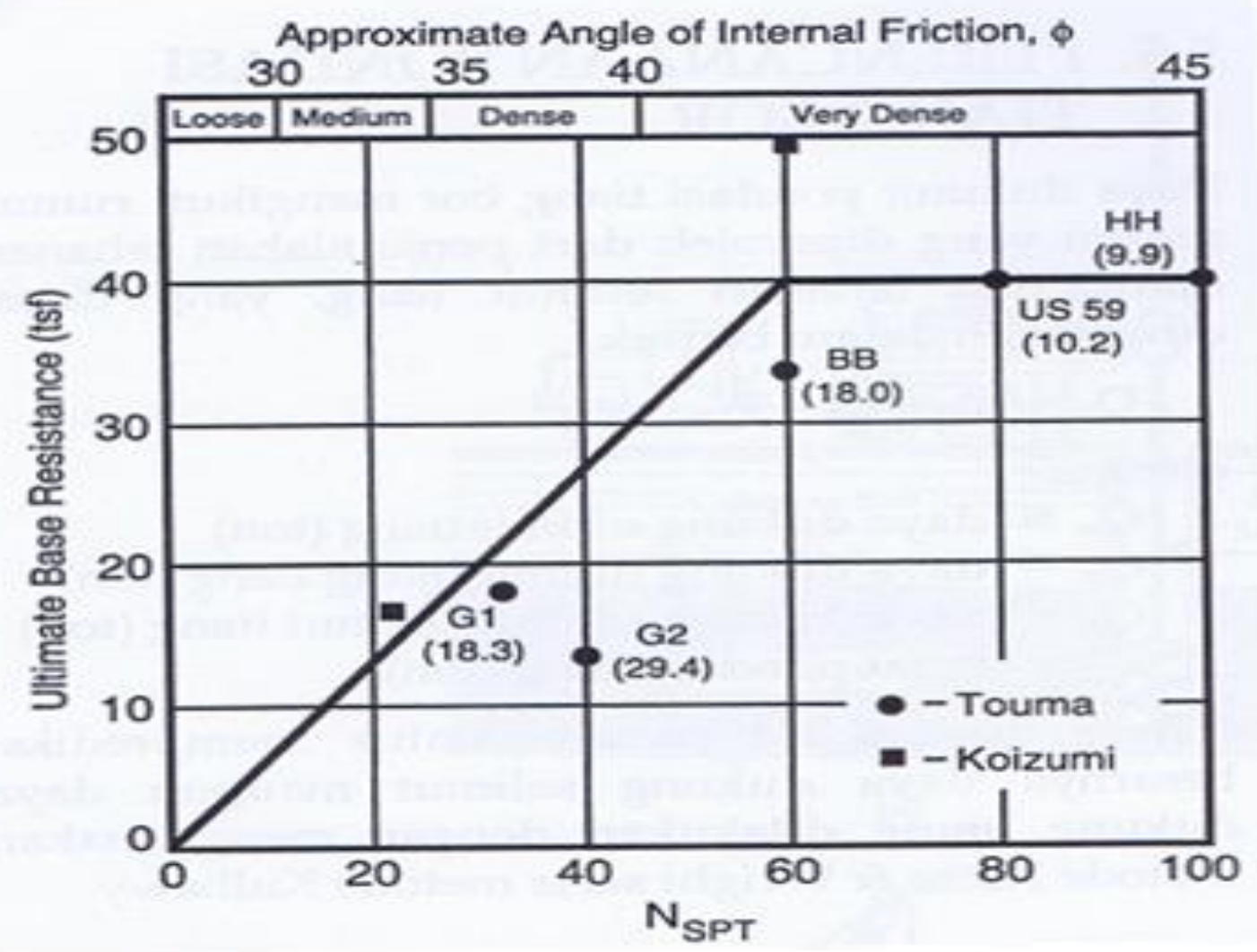

Gambar 2 Tahanan Ujung ultimit pada tanah non-kohesif (Reese, C. and Wright,1977)

Gambar 2 menunjukan grafis yang dipakai untuk Qp tanah non-kohesif, sedangkan untuk tanah kohesif menggunakan rumus berikut:

$$
\mathrm{Qp}=9 \times \mathrm{Su}
$$

Dengan $\mathrm{Qp}=$ daya dukung ultimit ujung tiang, dan $\mathrm{Su}=$ kuat geser.

Perhitungan daya dukung selimut dapat menggunakan rumus:

$$
\mathrm{Qs}=\mathrm{fs} \times \mathrm{l} \times \mathrm{p}
$$

Dengan Qs= daya dukung ultimit selimut tiang, fs = gesekan selimut tiang, $1=$ panjang tiang, dan $\mathrm{p}=$ keliling tiang.

Perhitungan daya dukung selimut pada tanah kohesif rumus fs yang dipakai adalah:

$$
\mathrm{fs}=\mathrm{a} \times \mathrm{Su}
$$

Dengan a $=0,55$ (faktor adhesi).

Untuk fs pada tanah non-kohesif fs bisa dilihat pada Gambar 3.

Perhitungan penurunan elastis menurut (Janbu, Nilmar and Bjerrum,1956) dirumuskan sebagai berikut:

$$
S_{i}=\mu_{i} \mu_{o} \frac{q B}{E}
$$

Dengan $S_{i}=$ penurunan segera, $\mu_{i}=$ faktor koreksi untuk lapisan tanah dengan tebal terbatas $H, \mu_{o}=$ faktor koreksi untuk kedalaman fondasi Df, $\mathrm{q}=$ tekanan netto fondasi $(\mathrm{P} / \mathrm{A}), \mathrm{B}=$ lebar tiang pancang kelompok, dan $\mathrm{E}=$ Modulus elastis. 
Untuk $\mu_{\mathrm{o}}$ dan $\mu_{\mathrm{i}}$ bisa didapat pada Gambar 4 .

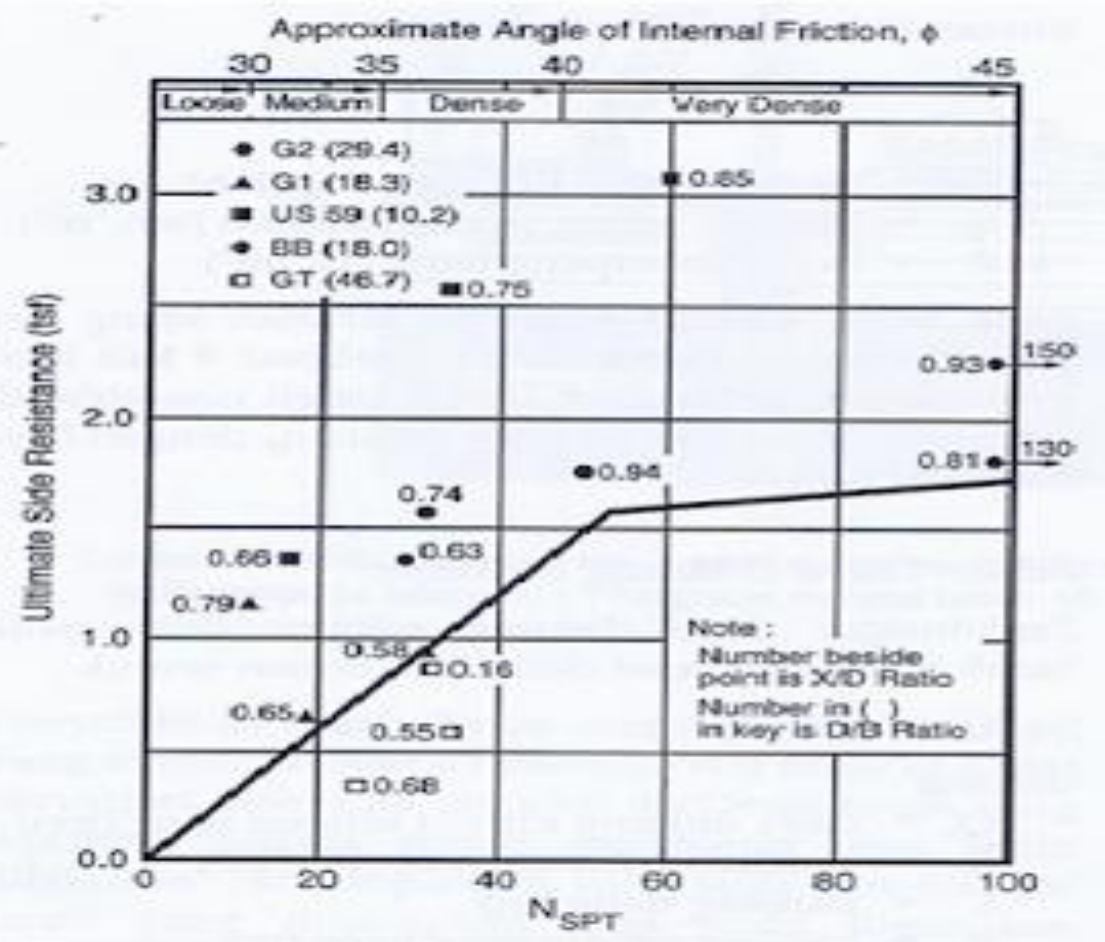

Gambar 3 Hubungan Tahanan selimut ultimit terhadap NSPT (Reese, C. and Wright,1977)

Efesiensi kelompok tiang dapat menggunakan rumus-rumus berikut:

1. Rumus Feld

2. Rumus Converse - Labarre

$$
\begin{gathered}
\eta=\left[\frac{4(13)+2(m+n-4)(11)+(m-2)(n-2)(8)}{16 m n}\right] \\
\eta=1-\left[\frac{(n-1) m+(m-1) n}{90 m n}\right] \theta \\
\eta=\left[\frac{2 s(m+n-2)+4 d}{p m n}\right]
\end{gathered}
$$$$
\eta=1-\left[\frac{365(m+n-2)}{\left(75 s^{2}-7\right)(m+n-1)}\right]+\frac{0,3}{m+n}
$$$$
\eta=1-d\left[\frac{(n-1) m+(m-1) n+(m-1)(n-1) \sqrt{2}}{\pi s m n}\right]
$$

Untuk penurunan primer memakai rumus dari buku (Das,2019) dengan menguji kondisi tanah tersebut apakah over consolidation atau normally consolidation sebagai berikut:

Bila $\sigma_{o}^{\prime}+\Delta \sigma^{\prime}>\sigma_{c}^{\prime}$ maka rumus:

$$
S_{p}=\frac{C_{c} H}{1+e_{o}} \log \left(\frac{\sigma^{\prime}{ }_{o}+\Delta \sigma \prime}{\sigma^{\prime} o}\right)
$$

$\sigma_{o}^{\prime}+\Delta \sigma^{\prime}<\sigma_{c}^{\prime}$ maka rumus

$$
S_{p}=\frac{C_{s} H}{1+e_{o}} \log \left(\frac{\sigma^{\prime}{ }^{\prime}+\Delta \sigma^{\prime}}{\sigma^{\prime}{ }_{o}}\right)
$$

$\sigma_{o}^{\prime}<\sigma_{c}^{\prime}<\sigma_{o}^{\prime}+\Delta \sigma^{\prime}$ maka rumus

$$
S_{p}=\frac{C_{S} H}{1+e_{o}} \log \frac{\sigma^{\prime} C}{\sigma^{\prime} o}+\frac{C_{C} H}{1+e_{o}} \log \left(\frac{\sigma^{\prime}{ }_{o}+\Delta \sigma^{\prime}}{\sigma^{\prime} o}\right)
$$


Dengan $C_{c}=$ indeks pemampatan tanah, $e_{o}=$ angka pori, $H=$ tebal lapisan tanah, $\sigma_{o}^{\prime}=$ tekanan overburden efektif, dan $\Delta \sigma^{\prime}=$ penambahan tekanan.

Untuk penurunan sekunder memakai rumus dari das sebagai berikut:

$$
S_{S}=\frac{C_{\alpha} H}{1+e} \log \left(\frac{t_{p}}{t_{f}}\right)
$$

Dengan $\mathrm{C}_{\alpha}=$ Indeks konsolidasi sekunder, $\mathrm{e}=$ Angka pori, $\mathrm{t}_{\mathrm{p}}=$ waktu akhir konsolidasi primer, dan $\mathrm{t}_{\mathrm{f}}=\mathrm{Umur}$ bangunan.
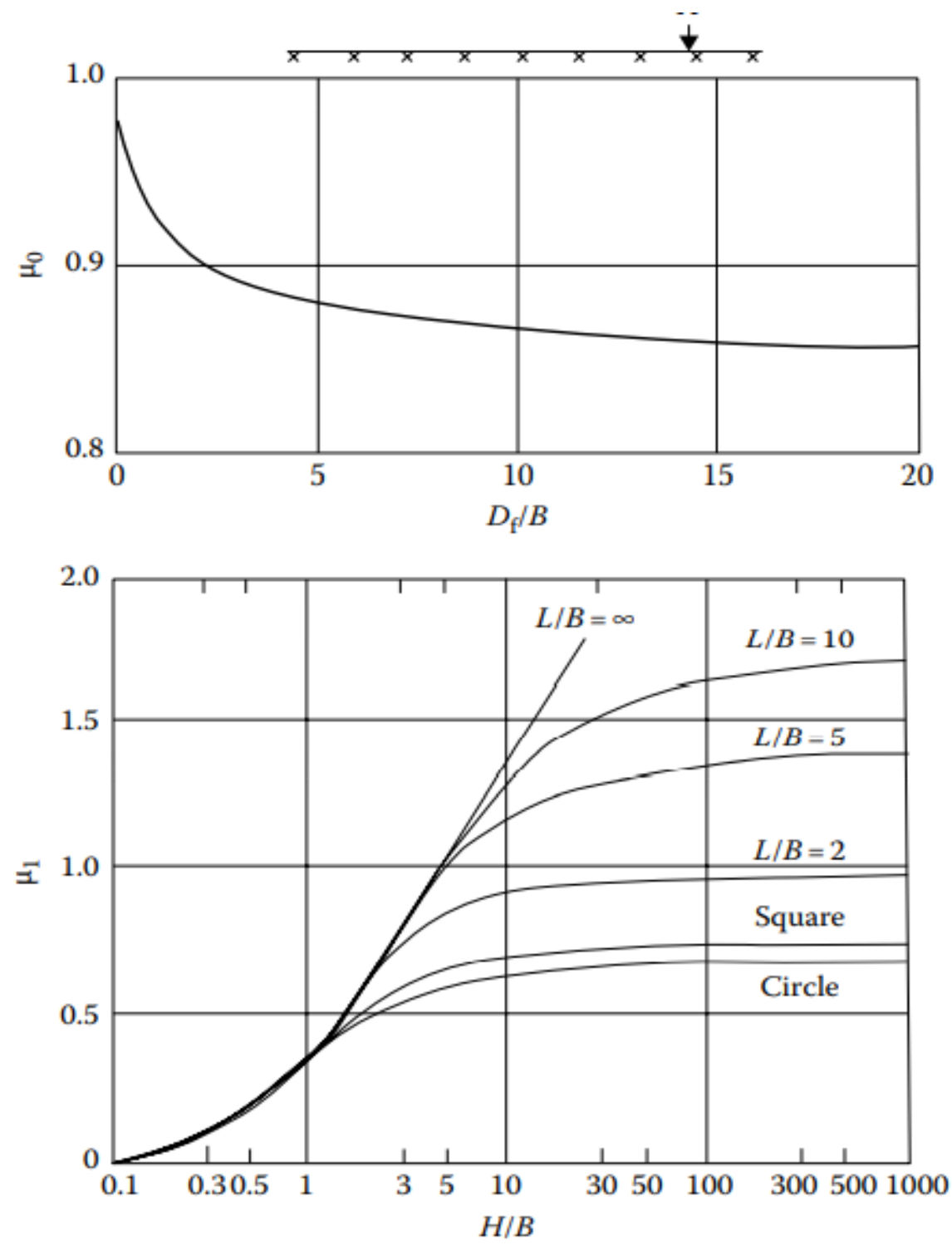

Gambar 4 Gambar Grafik faktor koreksi (Das,2019)

Dimana rumus tp:

$$
t_{p}=T v \times \frac{H^{2}}{C v}
$$

Dengan $\mathrm{Tv}=$ faktor waktu, dan $\mathrm{c}_{\mathrm{v}}=$ derajat konsolidasi.

Untuk mencari Tv bisa dipakai rumus berikut:

Untuk $\mathrm{U}>60 \%$

$$
T v=1,781-0,9333 * \log (100-U)
$$


Dengan $\mathrm{U}=$ derajat konsolidasi rata-rata.

\section{Pembahasan}

Penelitian ini membahas settlement pada fondasi tiang pada tanah bekas tempat pembuangan sampah sebelum dan sesudah perbaikan. Langkah awal setelah menentukan permasalahan yang akan dibahas yaitu pengumpulan studi literatur dengan permasalahan dan data penyelidikan tanah. Setelah data terkumpul dan diolah, langkah selanjutnya adalah perhitungan daya dukung fondasi dan penurunan. Metode yang digunakan untuk perhitungan menggunakan rumus empiris. Hasil yang didapatkan dibandingkan satu sama lain untuk mengetahui kelebihan dan kekurangan setiap metode perbaikan secara mekanis.

\section{HASIL DAN PEMBAHASAN}

Setelah dilakukan korelasi data dan perhitungan memakai rumus yang dicantumkan di bab 2 didapatkan Tabel 1 sebagai hasil perhitungan.

Tabel 1 Daya Dukung Selimut

\begin{tabular}{ccccccc}
\hline LAYER & $\begin{array}{c}\text { Depth } \\
(\mathrm{m})\end{array}$ & N-SPT & Jenis Tanah & $\begin{array}{c}\mathrm{Cu} \\
\left(\mathrm{t} / \mathrm{m}^{2}\right)\end{array}$ & $\begin{array}{c}\text { Fs } \\
\left(\mathrm{t} / \mathrm{m}^{2}\right)\end{array}$ & Qs (ton) $=$ Fs*P*L \\
\hline 1 & $0.00-0,61$ & 12 & Foundry Sand & - & 3,8278 & 8,798175206 \\
2 & $0,61-1,22$ & 22 & Foundry Sand & - & 7,1088 & 16,33946824 \\
3 & $1,22-1,83$ & 5 & Foundry Sand & - & 0,1094 & 0,251376434 \\
4 & $1,83-2,44$ & 5 & Sandy Silt & 30 & 16,5 & 37,92492 \\
5 & $2,44-3,05$ & 6 & Organic Soil & 35 & 19,25 & 44,24574 \\
6 & $3,05-3,66$ & 5 & Fibrous Peat & 30 & 16,5 & 37,92492 \\
7 & $3,66-4,27$ & 5 & Sandy Clay & 30 & 16,5 & 37,92492 \\
8 & $4,27-4,88$ & 17 & Sandy Clay & 85 & 46,75 & 107,45394 \\
9 & $4,88-5,49$ & 30 & Sandy Clay & 180 & 99 & 227,54952 \\
10 & $5,49-6,10$ & 41 & Silty Clay & 260 & 143 & 328,68264 \\
11 & $6,10-6,71$ & 54 & Silty Clay & 360 & 198 & 455,09904 \\
12 & $6,71-7,00$ & 58 & Silty Clay & 375 & 206,25 & 225,3735 \\
\hline & & & & & & $\sum 1538,116$ \\
\hline
\end{tabular}

Untuk daya dukung selimut memakai rumus 2 dan 3. Tabel perhitungan bisa dilihat di atas, daya dukung selimut total sebesar 1538,116 ton. Untuk daya dukung ujung tiang memakai rumus 1 karena ujung tanah terletak pada tanah kohesif, didapatkan nilai daya dukung ujung tiang sebesar 288 ton. Safety factor dipilih untuk ujung adalah 3 dan selimut 5 maka didapat daya dukung total yang sudah dikurangi dengan berat sendiri sebesar 384,6325 ton.

Tabel 2 Beban Bangunan

\begin{tabular}{ccccc}
\hline $\begin{array}{c}\text { Fy } \\
\text { Ton })\end{array}$ & $\begin{array}{c}\text { Fy } \\
\text { (Ton) }\end{array}$ & $\begin{array}{c}\text { Fz } \\
(\text { Ton })\end{array}$ & $\begin{array}{c}\text { Mx } \\
(\text { Tm })\end{array}$ & $\begin{array}{c}\text { My } \\
(\text { Tm })\end{array}$ \\
\hline 0,05 & 16,954 & 567,009 & 37,79 & 37,79 \\
\hline
\end{tabular}

Tabel 3 Efesiensi Kelompok Tiang

\begin{tabular}{ccccc}
\hline Feld & Converse-Labarre & Sederhana & Seileer Keeney & Los Angeles Group \\
\hline 0,9375 & 0,8788 & 1,4331 & 0,8268 & 0,9363 \\
\hline
\end{tabular}


Karena beban yang terdapat di Tabel 2 melebihi daya dukung total 1 tiang maka dibutuhkan 2 tiang untuk menahan beban bangunan, efesiensi dihitung memakai rumus 5 sampai 9, setelah dihitung(Tabel 3) dipilih angka paling kecil yaitu milik Seileer Keeney sebesar 0,8268 maka didapatkan daya dukung kelompok tiang sebesar 636,026 ton.

Tabel 4 Perhitungan Penurunan Elastis

\begin{tabular}{ccccccc}
\hline Layer & Tebal & $\mathrm{D}$ & $\mathrm{BG}$ & $\mathrm{LG}$ & $\mathrm{D} / \mathrm{BG}$ & $\mathrm{H} / \mathrm{Bg}$ \\
& $(\mathrm{m})$ & $(\mathrm{m})$ & $(\mathrm{m})$ & $(\mathrm{m})$ & & \\
\hline Layer 4' & 1,33 & 4,67 & 3,535 & 6,535 & 1,321075 & 0,376238 \\
Layer 5' & 1 & 6 & 4,865 & 7,865 & 1,233299 & 0,20555 \\
\hline
\end{tabular}

Tabel 5 Lanjutan Perhitungan Penurunan Elastis

\begin{tabular}{|c|c|c|c|c|c|c|}
\hline \multirow{2}{*}{ Layer } & \multicolumn{2}{|c|}{ Korelasi Grafis } & \multirow{2}{*}{$\begin{array}{l}\Delta \sigma^{\prime} \max \\
\left(\mathrm{kN} / \mathrm{m}^{2}\right)\end{array}$} & \multirow{2}{*}{$\begin{array}{l}\Delta \sigma^{\prime} \min \\
\left(\mathrm{kN} / \mathrm{m}^{2}\right)\end{array}$} & \multirow{2}{*}{$\begin{array}{c}\mathrm{S}_{\mathrm{e}} \max \\
(\mathrm{mm})\end{array}$} & \multirow{2}{*}{$\begin{array}{l}\mathrm{S}_{\mathrm{e}} \min \\
(\mathrm{mm})\end{array}$} \\
\hline & $\mu_{1}$ & $\mu_{0}$ & & & & \\
\hline Layer 4' & 0,92 & 0,15 & 371,3615 & 119,5294 & 2,131309 & 0,686 \\
\hline \multirow[t]{2}{*}{ Layer $5^{\prime}$} & 0,9 & 0,15 & 219,6248 & 76,74801 & 1,696989 & 0,593014 \\
\hline & & & & Total & 3,828298 & 1,279014 \\
\hline
\end{tabular}

Tabel 4 dan Tabel 5 merupakan tabel hasil perhitungan untuk penurunan elastis, perhitungan memakai rumus nomor 4 dan didapatkan penurunan paling maksimal sebesar 3,8282 $\mathrm{mm}$ untuk tanah tanpa perbaikan.

Tabel 6 Perhitungan Penurunan Primer

\begin{tabular}{cccccccc}
\hline Layer & $\begin{array}{c}\text { Tebal } \\
(\mathrm{m})\end{array}$ & $\begin{array}{c}\mathrm{D} \\
(\mathrm{m})\end{array}$ & $\begin{array}{c}\text { BG } \\
(\mathrm{m})\end{array}$ & $\begin{array}{c}\text { LG } \\
(\mathrm{m})\end{array}$ & Cc & Cs & e \\
\hline Layer 4' & 1,33 & 4,67 & 3,535 & 6,535 & 0,19 & 0,04 & \\
Layer 5' & 1 & 6 & 4,865 & 7,865 & 0,17 & 0,03 & 0,7 \\
\hline
\end{tabular}

Tabel 7 Lanjutan Perhitungan Penurunan Primer

\begin{tabular}{|c|c|c|c|c|c|c|c|}
\hline Layer & $\begin{array}{c}\sigma ’ 0 \\
\left(\mathrm{kN} / \mathrm{m}^{2}\right)\end{array}$ & $\begin{array}{c}\sigma^{\prime} \mathrm{o}+\Delta \sigma^{\prime} \max \\
\left(\mathrm{kN} / \mathrm{m}^{2}\right)\end{array}$ & $\begin{array}{c}\sigma^{\prime} \mathrm{o}+\Delta \sigma^{\prime} \min \\
\left(\mathrm{kN} / \mathrm{m}^{2}\right)\end{array}$ & $\begin{array}{c}\sigma^{\prime} \mathrm{c} \\
\left(\mathrm{kN} / \mathrm{m}^{2}\right)\end{array}$ & TIPE & $\begin{array}{c}\text { Sp max } \\
\text { mm }\end{array}$ & $\begin{array}{l}\text { Sp min } \\
\text { mm }\end{array}$ \\
\hline Layer 4' & 93,49862 & 464,86007 & 213,0280197 & 156,8 & $\mathrm{NC}$ & 100,5770 & 51,2954 \\
\hline Layer 5' & 101,3297 & 320,9545522 & 178,0777445 & 294,5 & $\mathrm{NC}$ & 50,07066 & 30,2001 \\
\hline & & & & & & 150,6477 & 81,4956 \\
\hline
\end{tabular}

Tabel 6 dan Tabel 7 merupakan tabel hasil penurunan primer, untuk penurunan primer perhitungan memakai rumus nomor 10, 11, \& 12 dan didapatkan hasil penurunan paling maksimal sebesar 150,6477 mm. 
Tabel 8 Perhitungan Penurunan Sekunder

\begin{tabular}{|c|c|c|c|c|c|c|c|c|c|c|}
\hline Layer & Tebal & $e$ & $\mathrm{Cv}$ & $\begin{array}{c}\mathrm{U} \\
(\%)\end{array}$ & $\mathrm{TV}$ & $\mathrm{s}$ & hari & $\begin{array}{c}\mathrm{tf} \\
\text { tahun }\end{array}$ & $\mathrm{Ca}$ & S \\
\hline Layer 4' & 1,33 & 0,75 & $5,3 \mathrm{E}-08$ & 90 & 0,848 & 28292387 & 327 & 50 & 0,0061 & 0,0081 \\
\hline \multirow[t]{3}{*}{ Layer 5' } & 1 & 0,7 & $5,7 \mathrm{E}-08$ & 90 & 0,848 & 14871930 & 172 & 50 & 0,0054 & 0,0065 \\
\hline & & & & & & & & & & 0,0145 \\
\hline & & & & & & & & & & $14,5497 \mathrm{~mm}$ \\
\hline
\end{tabular}

Pada Tabel 8 dapat dilihat hasil perhitungan penurunan sekunder, untuk penurunan sekunder perhitungan memakai rumus nomor $13,14,15, \& 16$ dan didapatkan penurunan sebesar $14,5497 \mathrm{~mm}$.

Untuk penurunan total sebelum perbaikan didapatkan dengan menjumlah penurunan elastis, penurunan primer, dan penurunan Sekunder. Jumlah penurunan total yang didapatkan adalah sebesar 169,0267 mm.

Untuk Stone Column daya dukung didapatkan dengan rumus:

$$
\mathrm{qu}=\mathrm{c} \cdot \mathrm{Nc}+\mathrm{q} \cdot \mathrm{Nq}+1 / 2 \cdot \mathrm{w} \cdot \gamma \cdot \mathrm{N} \gamma
$$

dengan $\mathrm{qu}=$ daya dukung, $\mathrm{c}=$ kohesi, $\mathrm{q}=$ beban, $\mathrm{w}=$ kadar air, dan $\gamma=$ berat jenis.

untuk variasi $\mathrm{Nc}, \mathrm{Nq}$, dan $\mathrm{N} \gamma$ didapat dari korelasi Gambar 5, Gambar 6 dan Gambar 7 dibawah.

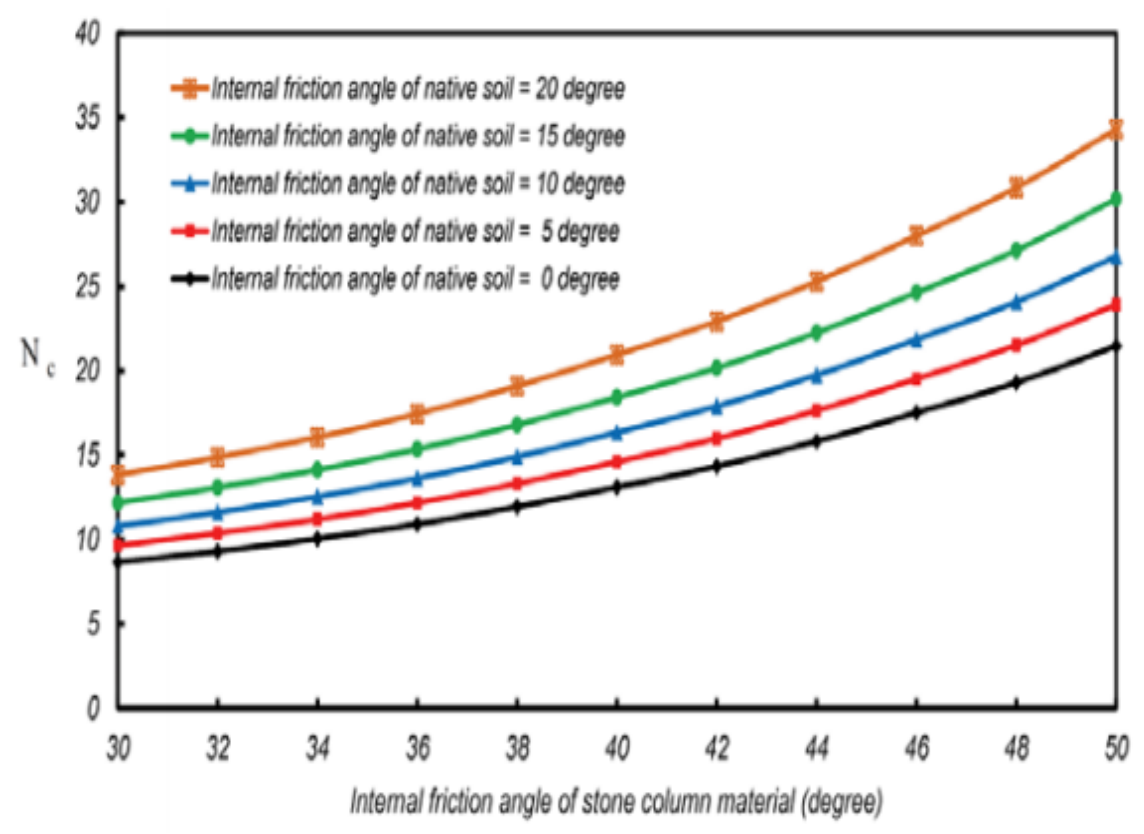

Gambar 5 Korelasi Variasi Nc (Nazari Afshar and Ghazavi,2014) 


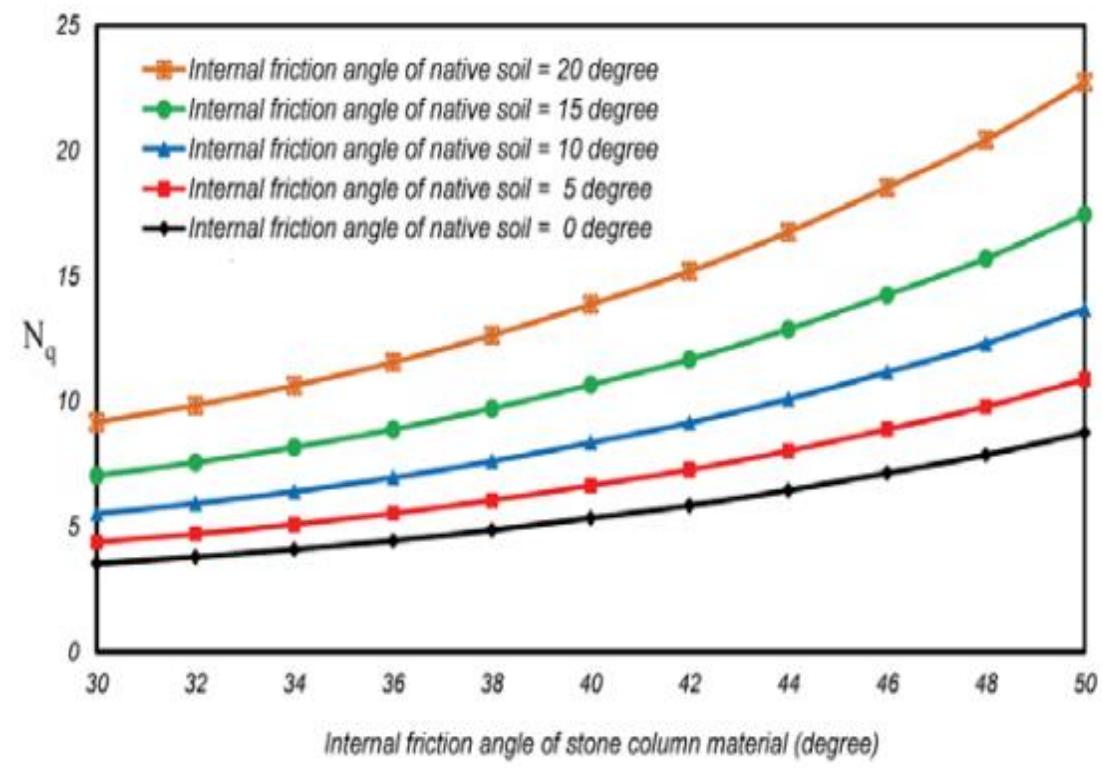

Gambar 6 Korelasi Variasi Nq (Nazari Afshar and Ghazavi,2014)

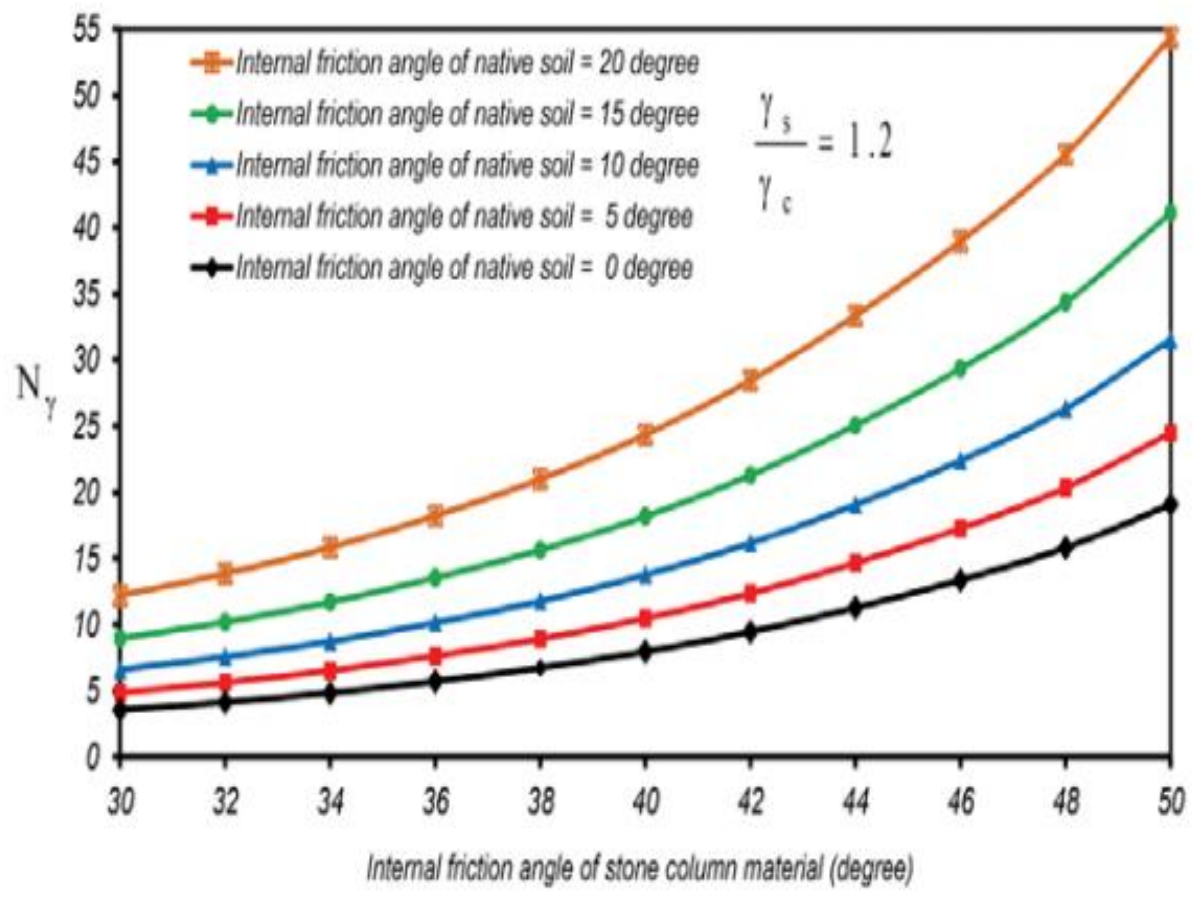

Gambar 7 Korelasi Variasi N $\gamma$ (Nazari Afshar and Ghazavi,2014)

Dari perhitungan didapatkan daya dukung sebesar 9653,444 ton. 


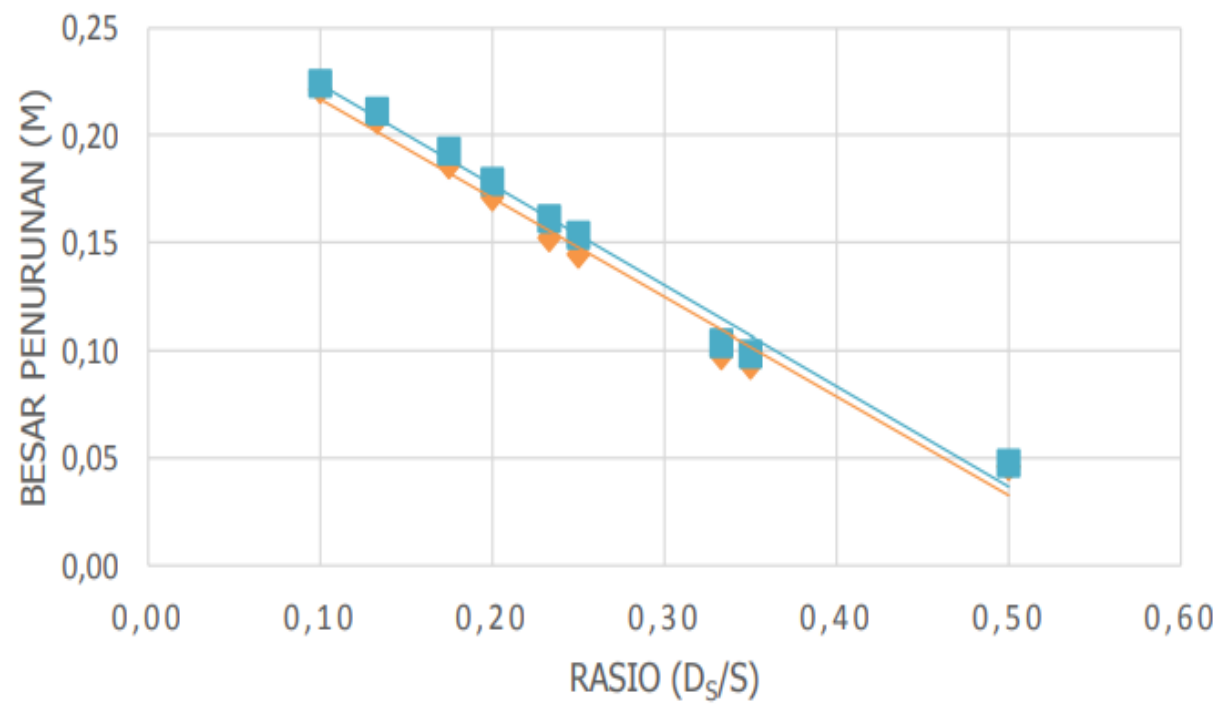

Gambar 8 Korelasi Penurunan \& Replacement Area Ratio (Nazari Afshar and Ghazavi,2014)

Dari Gambar 8 didapatkan besar penurunan sebesar 0,0095 mm.

Untuk daya dukung Dynamic Compaction (DC) secara umum akan mengalami peningkatan sebesar 60\% (Ali and Ali,2008).Maka didapat daya dukung sebesar 615,412 ton.

Settlement untuk tanah kohesif yang diperbaiki menggunakan Dynamic Compaction memiliki karakteristik peningkatan Cc sebesar 2,7 kali (Kundu, Saptarshi and Viswanadham,2020). Maka penurunan yang dipengaruhi adalah tipe primer dengan besar total penurunan sebesar $425.1279 \mathrm{~mm}$ jika penurunan primer baru dijumlah dengan penurunan elastis dan sekunder, perhitungan tercantum di tabel di bawah, perhitungan bisa dilihat pada Tabel 9 dan Tabel 10 .

Tabel 9 Perhitungan Primer (DC)

\begin{tabular}{cccccccc}
\hline Layer & $\begin{array}{c}\text { Tebal } \\
(\mathrm{m})\end{array}$ & $\begin{array}{c}\mathrm{D} \\
(\mathrm{m})\end{array}$ & $\begin{array}{c}\text { BG } \\
(\mathrm{m})\end{array}$ & $\begin{array}{c}\text { LG } \\
(\mathrm{m})\end{array}$ & Cc & Cs & e \\
\hline Layer 4' & 1,33 & 4,67 & 3,535 & 6,535 & 0,513 & 0,04 & 0,75 \\
Layer 5' & 1 & 6 & 4,865 & 7,865 & 0,459 & 0,03 & 0,7 \\
\hline
\end{tabular}

Tabel 10 Lanjutan Perhitungan Primer (DC)

\begin{tabular}{|c|c|c|c|c|c|c|c|}
\hline Layer & $\begin{array}{c}\sigma ’ o \\
\left(\mathrm{kN} / \mathrm{m}^{2}\right)\end{array}$ & $\begin{array}{c}\sigma^{\prime} \mathrm{o}+\Delta \sigma^{\prime} \max \\
\left(\mathrm{kN} / \mathrm{m}^{2}\right)\end{array}$ & $\begin{array}{c}\sigma^{\prime} \mathrm{o}+\Delta \sigma^{\prime} \min \\
\left(\mathrm{kN} / \mathrm{m}^{2}\right)\end{array}$ & $\begin{array}{c}\sigma^{\prime} \mathrm{c} \\
\left(\mathrm{kN} / \mathrm{m}^{2}\right)\end{array}$ & TIPE & $\begin{array}{l}\text { Sp max } \\
(\mathrm{mm})\end{array}$ & $\begin{array}{l}\text { Sp min } \\
(\mathrm{mm})\end{array}$ \\
\hline Layer 4' & 93,49862 & 464,86007 & 213,0280197 & 156,8 & $\mathrm{NC}$ & 271,558 & 138,498 \\
\hline \multirow[t]{2}{*}{ Layer 5' } & 101,3297 & 320,9545522 & 178,0777445 & 294,5 & $\mathrm{NC}$ & 135,191 & 81,540 \\
\hline & & & & & & 406,749 & 223,038 \\
\hline
\end{tabular}

Untuk PVD dari penelitian didapatkan peningkatan penurunan sebesar $15 \%$ dan disaat bersamaan mereduksi waktu konsolidasi sebesar 98\%. Untuk daya dukung secara tipikal PVD akan meningkatkan daya dukung tanah sebesar kurang lebih 2 kali lipat (Saraswati, Ika and Zaika,2018), hasil bisa dilihat pada Tabel 11dan Tabel 12.

Tabel 11 Daya Tanah Sebelum PVD

\begin{tabular}{ccc}
\hline Penurunan & Daya Dukung & Waktu \\
\hline $169,0267 \mathrm{~mm}$ & 384,6325 ton & 327 hari \\
\hline
\end{tabular}


Tabel 12 Daya Tanah Sesudah PVD

\begin{tabular}{ccc}
\hline Penurunan & Daya Dukung & Waktu \\
\hline $194,3807 \mathrm{~mm}$ & 769,265 ton & 7 hari \\
\hline
\end{tabular}

\section{KESIMPULAN DAN SARAN}

Kesimpulan yang dapat diambil dari penelitian ini yaitu :

1. Penurunan yang paling berpengaruh adalah penurunan primer dengan besar penurunan $150,6477 \mathrm{~mm}$ dibandingkan dengan penurunan elastis dengan besar nilai 3,829 $\mathrm{mm}$ dan penurunan sekunder sebesar $14,5497 \mathrm{~mm}$

2. Daya dukung tanah sebelum mengalami perbaikan adalah sebesar 384,6325 ton dan besar penurunan yang terjadi adalah $169,0267 \mathrm{~mm}$

3. Besar daya dukung tanah setelah mengalami perbaikan dapat dilihat pada Tabel 13

Tabel 13 Summary Daya Dukung

\begin{tabular}{rrcc}
\hline Tanpa Perbaikan & Stone Column & Dynamic Compaction & Prefabricated Vertical Drain \\
\hline 384,6325 ton & 9653,444 ton & 615,412 ton & 769,265 ton \\
\hline
\end{tabular}

4. Besar Penurunan tanah setelah mengalami perbaikan dapat dilihat pada Tabel 14

Tabel 14 Summary Penurunan

\begin{tabular}{cccc}
\hline Tanpa Perbaikan & Stone Column & Dynamic Compaction & Prefabricated Vertical Drain \\
\hline $169,0267 \mathrm{~mm}$ & $95 \mathrm{~mm}$ & $425.1279 \mathrm{~mm}$ & $194,3807 \mathrm{~mm}$ \\
\hline
\end{tabular}

5. Dari penelitian bisa disimpulkan bahwa perbaikan Stone Column merupakan perbaikan yang paling tepat untuk tanah Tempat Pembuangan Akhir (TPA). Hal ini bisa dilihat dari jumlah penurunan yang paling kecil dibanding dengan perbaikan tanah lainya.

6. Alasan Stone Column efektif adalah karena prinsip fungsinya yang mendistribusi tegangan akibat beban yang disalurkan melalui ke lapisan tanah di sekitar kolom. Sifat Stone Column yang berinteraksi dengan tanah disekitar akan memperkuat struktur tanah sehingga perpindahan yang diakibatkan oleh penurunan menjadi lebih kecil.

7. Alasan PVD lebih efektif dibandingkan dengan stone column adalah karena prinsip kerjanya yang memanfaatkan tekanan dari tanah sendiri untuk mengekstrak air dari tanah. Untuk tanah TPA yang mengandung lindi, dengan pengaplikasian PVD lindi tersebut bisa diekstrak sehingga akan meninggalkan ruang hampa. Ruang hampa ini akan mengalami penurunan. Penurunan bisa terjadi karena berat tanah sendiri atau timbunan yang dipasang diatas.

8. Dynamic Compaction tidak efektif karena perbaikan tanah ini lebih diarahkan kepada tanah nonkohesif(pasir). Ketika tanah TPA diperbaiki kemungkinan tanah akan menyebar dan saling memadatkan daerah disekitarnya lebih kecil karena sifat tanah yang mengarah ke tanah kohesif.

Saran yang dapat diambil dari penelitian ini yaitu:

1. Penelitian lapangan dilakukan untuk memastikan data hitungan dengan data lapangan.

2. Penelitian ini bisa dijadikan sebagai dasar untuk memulai penelitian yang lebih ekstensif. 
3. Menggunakan software sebagai pembanding hasil perhitungan manual yang telah dilakukan.

4. Penelitian dijadikan sebagai referensi karena data tanah yang dipakai merupakan data tanah dari Amerika dan tidak mengrefleksikan kondisi tanah Indonesia dengan sesuai.

\section{DAFTAR PUSTAKA}

Ali, Liaqat dan Sarfraz Ali. "Enhancement of Bearing Capacity by Dynamic Compaction: A Case History." 6th Conference of the International Conference on Case Histories in Geotechnical Engineering (2008).

Darwis, H. Dasar-dasar Teknik Perbaikan Tanah. Yogyakarta: Pustaka AQ , 2017.

Das, Braja M. “Advanced soil mechanics.” Crc Press, 2019.

Fulmer, Shane. https://worldpopulationreview.com. 1 Januari 2015. 18 Agustus 2020.

Gerth, André, et al. "Reuse of a closed landfill site for installation and operation of a biomass utilization plant." International Conference on Advanced Technology and Sustainable Development, International Symposium on Green Technology, . Kaoshiung, 2016.

Janbu, et al. Veiledning ved lфsning av fundamenteringsoppgaver. 1956.

Jedele, Larry P dan Brandon Buschmeier. “Ground Improvement for Redevelopment of Former Landfill.” (2013).

Kundu, Saptarshi dan B. V. S. Viswanadham. "Numerical Modeling of Dynamic Compaction Induced Settlement of MSW Landfills.” International Journal of Geomechanics 20.8 (2020).

Nazari Afshar, J. dan Mahmoud Ghazavi. "A simple analytical method for calculation of bearing capacity of stone-column." International Journal of Civil Engineering 12.1 (2014): 15-25.

Reese, et al. "Drilled shaft design and construction guidelines manual. Vol. 1." Washington D.C: U.S Department of Transportation, Federal Highway Administration, Offices of Research and Development, Implementation Division, 1977.

Russ, John C. “Ground improvement.” CRC Press, 2012.

Saraswati, et al. "Perencanaan Perbaikan Tanah Lunak pada Pembangunan Kawasan Kota Summarecon Bandung Area Mall Menggunakan Metode Preload Kombinasi PVD dan PHD.” Jurnal Mahasiswa Jurusan Teknik Sipil 1.1 (2018): 0-19.

Seoul Metropolitan Government. https://seoulsolution.kr/. 20 Juni 2015. 20 Agustus 2020.

Yoo, Kee-young, Won-ju Kim dan Kyu-yi Kang. "Nanjido eco park restoration from waste dumping site." Knowledge Sharing Program: KSP Modularization (2014). 